\title{
Numerical modelling and analysis of influence of engine operating variable on engine emission using MATLAB
}

\author{
Neelakrishnan Subramanian, Karthikeyan Rangaraju ${ }^{1}$ \\ \{ns.auto@psgtech.ac.in ${ }^{1}$, kkr.auto@psgtech.ac.in $\left.{ }^{2}\right\}$ \\ Department of Automobile Engineering, PSG College of Technology, Coimbatore-641 $004^{1}$
}

\begin{abstract}
The numerical modelling of influence of engine design and operating variables such as types of fuels, calorific value, piston bowl diameter and emission variables on engine emission have been developed through empirical equation, the equation have been constituted with variables and were obtained from the engine test results. The MATLAB coding has been developed with respect to available testing data. The developed model have shown the results agreed with closest to the real time values. Therefore the influence of piston bowl diameter, calorific value and various types fuels such as isobutanol, methanol, ethanol and gasoline on NOx emission have been simulated with the help of developed model. The results were seen closest to the real time value.
\end{abstract}

Keywords: Engine, Emission, Nox, MATLAB.

\section{Introduction}

This work deals with the influence of the engine design and operating variables on engine emission. In each field various literatures are collected and analysed. In each literature information about the experiment conducted, results obtained, parameters affect their research work, remedies taken to recover their work, future scope of the work and the limitation of their research work are clearly depicted [1,2].

B.M. Masum n , H.H. Masjuki, M.A. Kalam, I.M. Rizwanul Fattah, S. M Palash, M.J. Abedin[3] their work on the effect of a mix of ethanol and gasoline on NOx emissions in a SI engine " which provides the information on because of finite fossil fuel supplies and environmental concerns, alternative fuels are becoming increasingly crucial for automobiles. Ethanol is an alternative fuel that has been utilised for several years in a number of nations since it is made from renewable resources and emits fewer emissions. Although using ethanol in SI engines decreases $\mathrm{CO}, \mathrm{HC}$, and other pollutants, there are some discrepancies in NOx emissions, as numerous researches have demonstrated.

The heating value, latent heat of vaporisation, oxygen concentration, laminar flame velocity, and other physicochemical characteristics of ethanol-gasoline blends have a major role in NOx production in SI engines.

"The effects of using different butanol-gasoline blends on performance, fuel consumption, and emissions of a four cylinder SI engine operated at low and high throttle positions as well as low and high engine speeds have been experimentally studied," according 
to Tan Tien Huynh et al's work on Effects of butanol-gasoline blends on SI engine performance, fuel consumption, and emission characteristics at partial engine speeds. Without any modifications to the engine, the fame speed of the butanol-gasoline blends drops as the butanol-blending percentage increases at high throttle positions. As the engine speed increases, this becomes more apparent. Because the butanol percentage is less than $30 \%$, the engine braking torque and engine power are enhanced, and the specific fuel consumption is reduced as compared to pure gasoline under low throttle conditions. When the butanolblending percentage exceeds $30 \%$ at 30 percent of WOT, the braking torque drops somewhat while the RAFR rises rapidly. As the butanol-gasoline blend ratio is increased, the braking torque steadily decreases at 70 percent of WOT.

Prof. DSc. DEng. Krzysztof Wisocki, Faculty of Machines and Transport, Poznan University of Technology. Their work on Optical analysis of combustion chamber and fuel spray interaction in terms of chamber geometry modification and injection parameter changes provides information "to optimise flex-fuel internal combustion engines in order to encourage the use of alcohol fuels, accurate simulation models are required." Internal combustion engines, with their many degrees of freedom, are getting increasingly complicated.The models must accurately reflect the effects of various alcohol-gasoline mixes on engine processes. As a result, the objective of this research is to create a modelling tool that can forecast the performance of spark ignition engines running on alcohol-gasoline mixes in both normal and pathological combustion modes (knock).

The objective of this work is to determine the relation between the emission variables [Nox] and the respective engine operating variables[calorific value, rpm, fuels] and the respective engine design variables[bowl auxiliary diameter] in the form of equation with the help of MATLAB using curve fitting. Values required for curve fitting are taken from [1],[2]. The characteristic of the above variables within the given range are studied using the graph.

Methods and simulation

The various influential parameters such as emission, engine operating variables and engine design variables were collected from the respective experimental results and the numerical modelling have been done with the help of MATLAB software. The required data of emission parameter for curve fitting in MATLAB have been collected from the emission test and engine characteristic test results [6,7]. The data collection has been done for NOx value in various fuels and corresponding engine RPM, the four types of fuels were implemented for the data collection are methanol, ethanol, iso-butanol and gasoline.

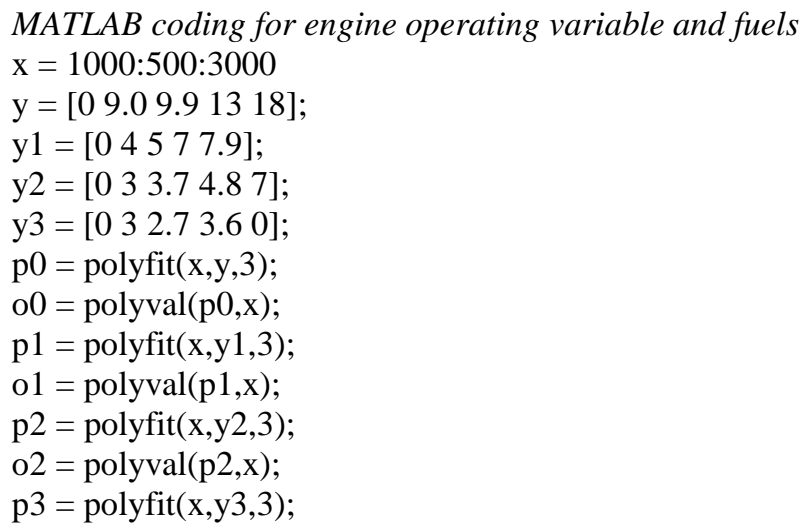




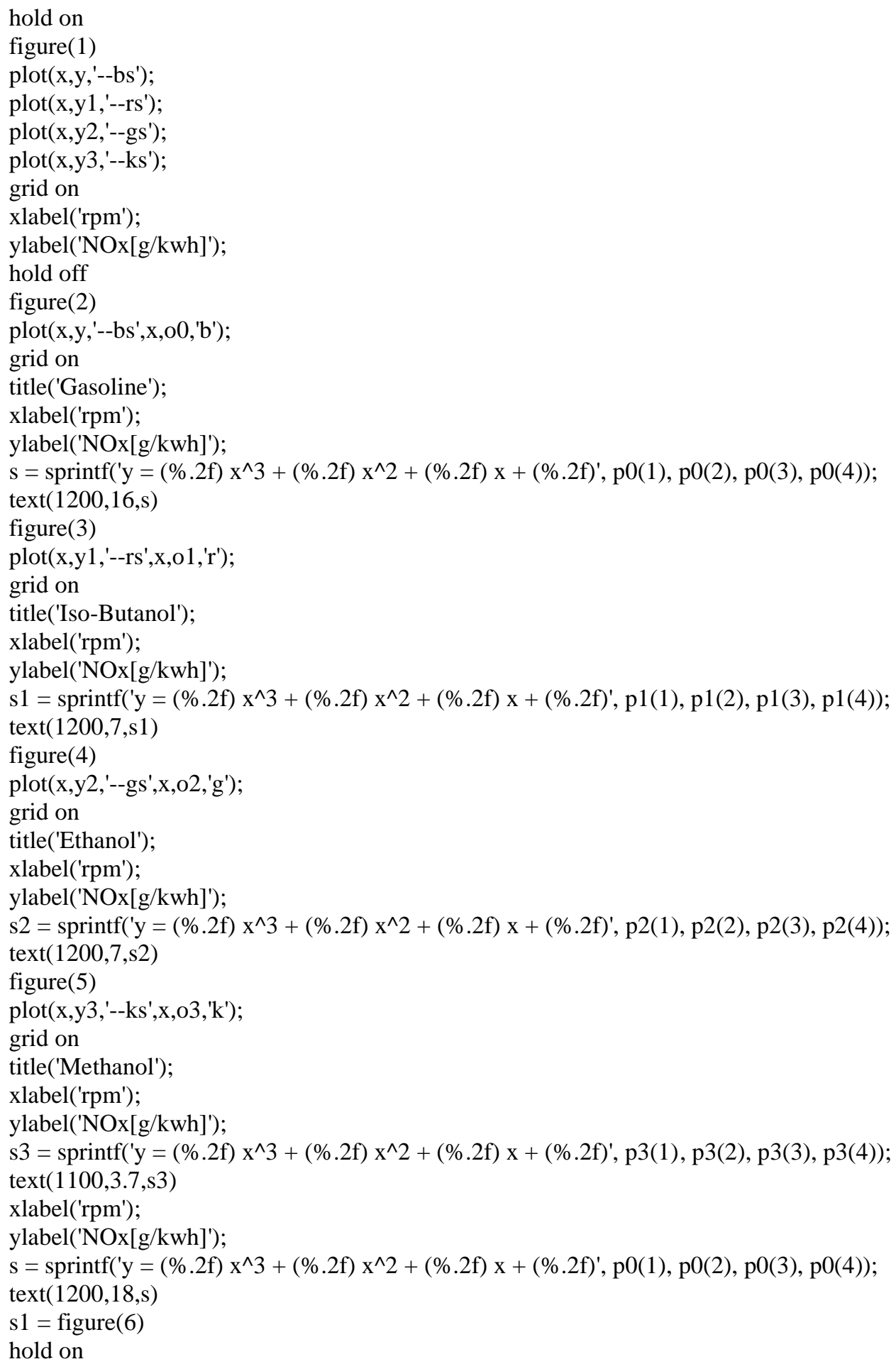




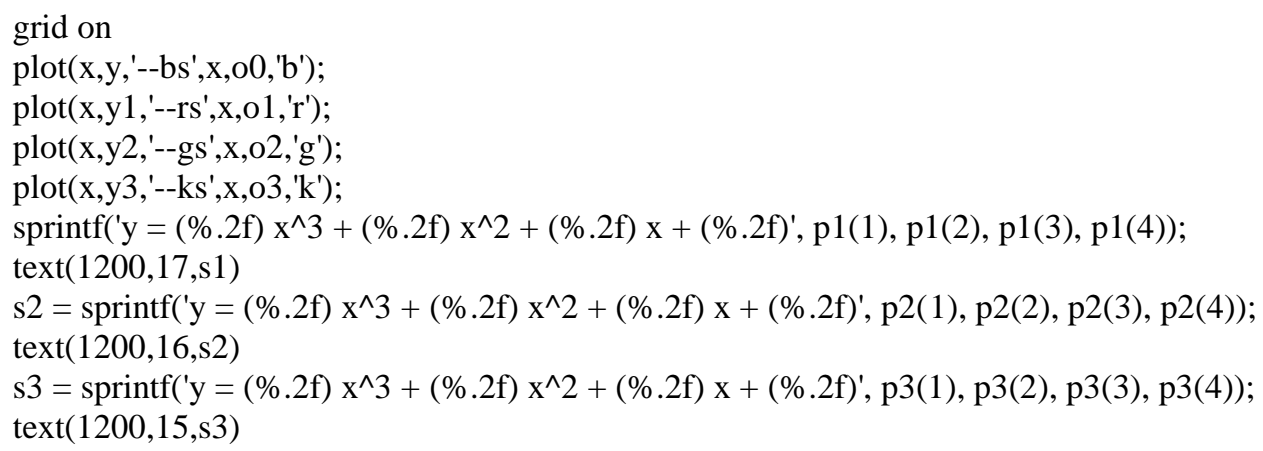

MATLAB coding for engine operating variable and calorific value

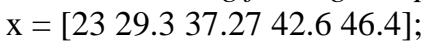

$\mathrm{y}=\left[\begin{array}{lllll}3 & 5 & 14 & 7 & 13\end{array}\right]$;

$\mathrm{p} 0=\operatorname{polyfit}(\mathrm{x}, \mathrm{y}, 3)$

$\mathrm{o} 0=\operatorname{polyval}(\mathrm{p} 0, \mathrm{x})$

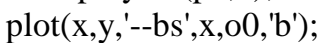

grid on

xlabel('CF');

ylabel('NOx');

$\mathrm{s}=\operatorname{sprintf}\left({ }^{\prime} y=(\% .2 \mathrm{f}) \mathrm{x}^{\wedge} 3+(\% .2 \mathrm{f}) \mathrm{x}^{\wedge} 2+(\% .2 \mathrm{f}) \mathrm{x}+(\% .2 \mathrm{f})^{\prime}, \mathrm{p} 0(1), \mathrm{p} 0(2), \mathrm{p} 0(3), \mathrm{p} 0(4)\right) ;$ text $(25,12, \mathrm{~s})$

MATLAB coding for engine design variable and piston bowl diameter

$\mathrm{x}=45: 2: 51$

$\mathrm{y}=\left[\begin{array}{llll}36 & 30 & 28 & 30.5\end{array}\right]$;

$\mathrm{p} 0=\operatorname{polyfit}(\mathrm{x}, \mathrm{y}, 3)$;

$\mathrm{o} 0=\operatorname{polyval}(\mathrm{p} 0, \mathrm{x})$;

plot(x,y,'--bs',x,o0,'b');

grid on

xlabel('Dr');

ylabel('NOx');

$\mathrm{s}=\operatorname{sprintf}\left(' y=(\% .2 \mathrm{f}) \mathrm{x}^{\wedge} 3+(\% .2 \mathrm{f}) \mathrm{x}^{\wedge} 2+(\% .2 \mathrm{f}) \mathrm{x}+(\% .2 \mathrm{f})^{\prime}, \mathrm{p} 0(1), \mathrm{p} 0(2), \mathrm{p} 0(3), \mathrm{p} 0(4)\right) ;$ $\operatorname{text}(47,35, \mathrm{~s})$

\section{Results and Discussion}

For pure fuels, trends in emissions of ethanol, methanol, ISO-butanol, and gasoline are illustrated and discussed. The NOx emissions for the four different fuels are given in Figure 1.1 at a fixed load of $75 \mathrm{Nm}$ and a variety of engine speeds. The largest NOx emissions come from gasoline, whereas the lowest come from methanol. Ethanol and butanol emit NOx in the same range as gasoline and methanol. Because most NOx is created by the thermal process, which is highly reliant on temperature, the lower combustion temperature of alcohol fuels is responsible for reduced NOx emissions. 
The equation have derived from the MATLAB software is given in equation. 1 for ethanol fuel operation

$\mathrm{y}=(0.00) \mathrm{x}^{3}+(-0.00) \mathrm{x}^{2}+(0.03) \mathrm{x}+(-18.10)$ eq $(1)$

where $\mathrm{x}=$ calorific value $[\mathrm{MJ} / \mathrm{kg}]$

$\mathrm{y}=\mathrm{NOx}[\mathrm{g} / \mathrm{kWh}]$

For the pure fuel, the trends in ethanol emissions are displayed and explained. The NOx emissions with a constant load of $75 \mathrm{Nm}$ and a variety of engine speeds are illustrated in Figure 1.

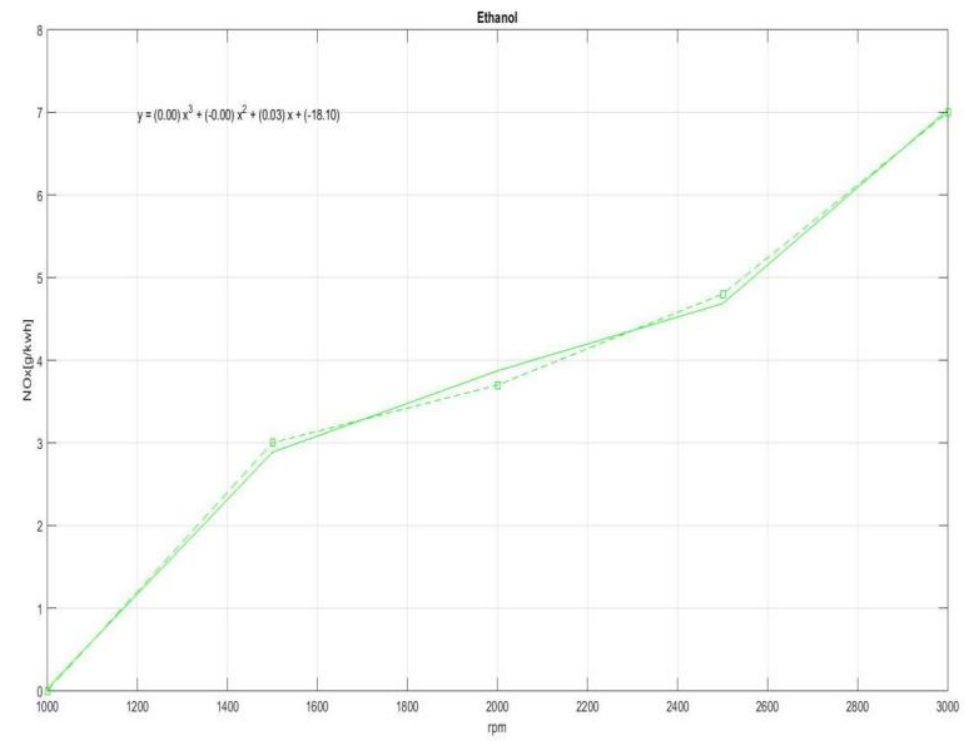

Figure.1. NOx and engine speed (type of fuel : ethanol)

The equation have derived from the MATLAB software is given in equation.2 for isobutanol fuel operation

$\mathrm{y}=(0.00) \mathrm{x}^{3}+(-0.00) \mathrm{x}^{2}+(0.02) \mathrm{x}+(-15.92) \mathrm{eq}(2)$

where $\mathrm{x}=$ calorific value $[\mathrm{MJ} / \mathrm{kg}] \mathrm{y}=\mathrm{NOx}[\mathrm{g} / \mathrm{kWh}]$ 
For the pure fuel, the patterns of ISO-butanol emissions are displayed and discussed. Figure 2 depicts NOx emissions at a fixed load of $75 \mathrm{Nm}$ and a variety of engine speeds.

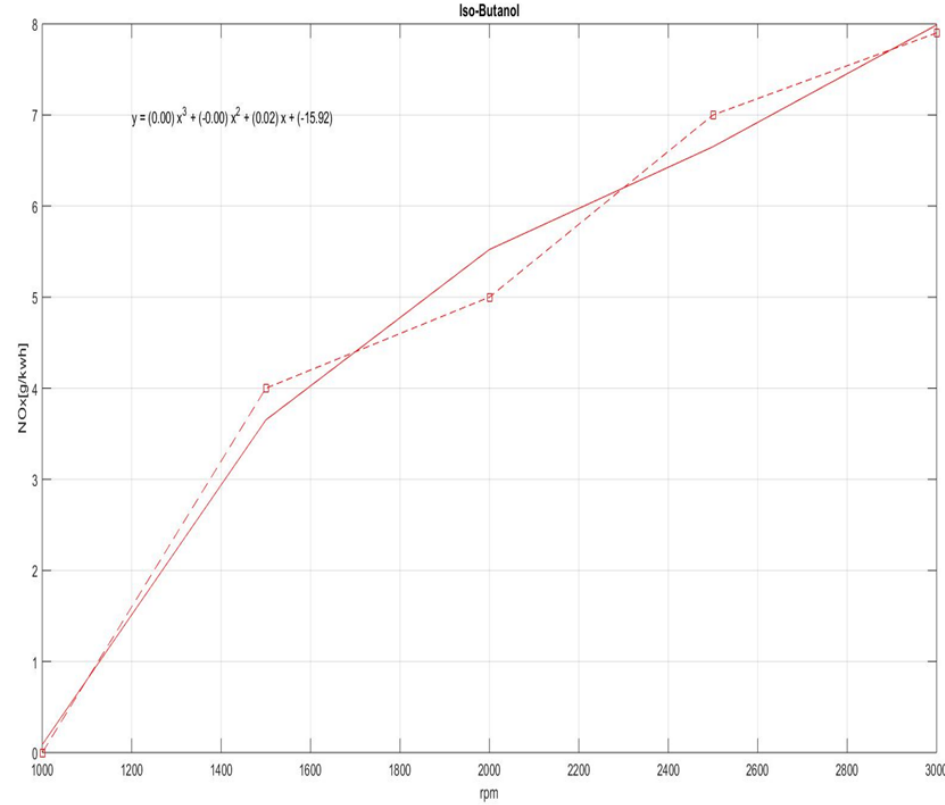

Figure.2. NOx and engine speed (type of fuel :Isobutanol)

The equation have derived from the MATLAB software is given in equation.3 for gasoline operation

$\mathrm{y}=(0.00) \mathrm{x}^{3}+(-0.00) \mathrm{x}^{2}+(0.09) \mathrm{x}+(-53.82)$ eq $(3)$

where $\mathrm{x}=$ calorific value $[\mathrm{MJ} / \mathrm{kg}] \mathrm{y}=\mathrm{NOx}[\mathrm{g} / \mathrm{kWh}]$

For the pure fuel, the patterns of ISO-butanol emissions are displayed and discussed. Figure 2 depicts NOx emissions at a fixed load of $75 \mathrm{Nm}$ and a variety of engine speeds. 


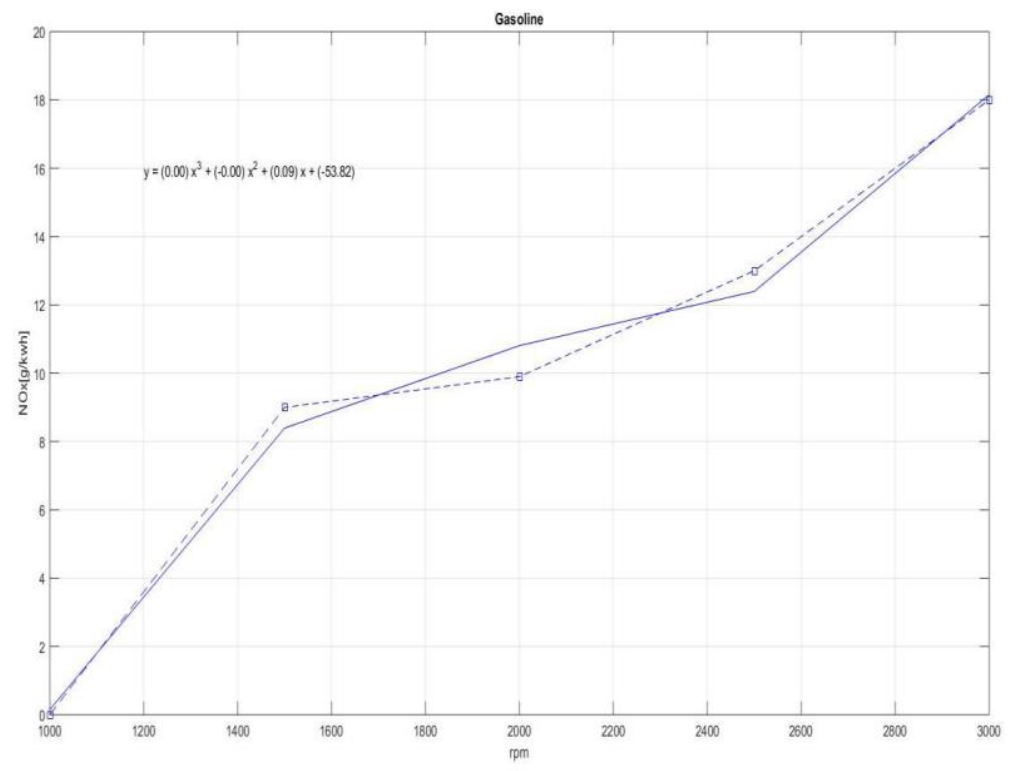

Figure.3. NOx and engine speed (type of fuel: Gasoline)

The equation have derived from the MATLAB software is given in equation.4 for methanol fuel operation

$\mathrm{y}=(0.00) \mathrm{x}^{3}+(-0.00) \mathrm{x}^{2}+(0.00) \mathrm{x}+(-5.34) \mathrm{eq}(4)$

Where, $\mathrm{x}=$ Speed $(\mathrm{RPM}) \cdot \mathrm{y}=\mathrm{NOx}[\mathrm{g} / \mathrm{kWh}]$

For the pure fuel, the patterns of ethanol emissions are illustrated and explained. Figure 4 depicts NOx emissions at a fixed load of $75 \mathrm{Nm}$ and a variety of engine speeds.

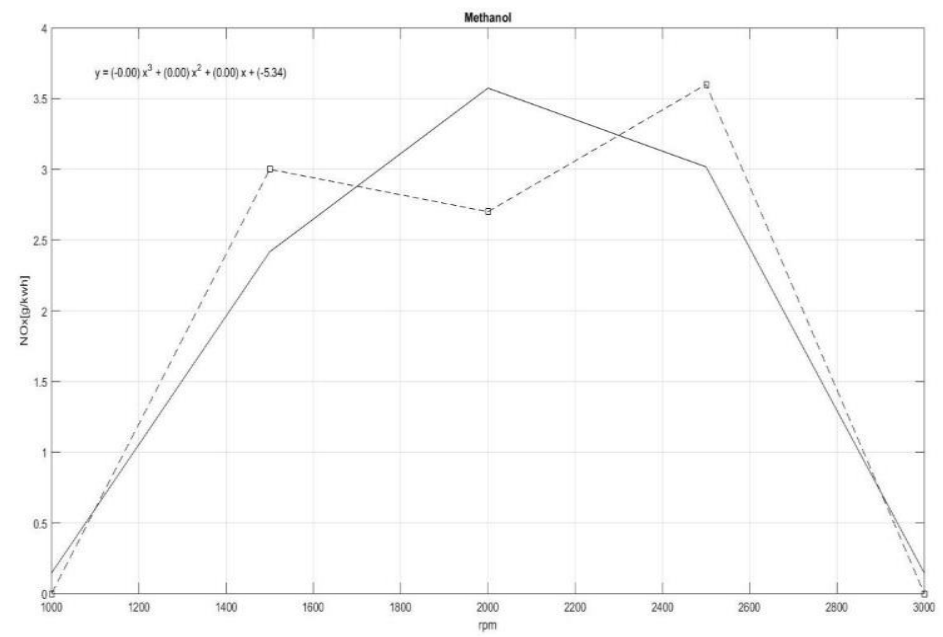

Figure.4. NOx and engine speed (type of fuel: Methanol) 
The equation have derived from the MATLAB software is given in equation.5 for different calorific value

$$
\mathrm{y}=(0.00) \mathrm{x}^{3}+(-0.05) \mathrm{x}^{2}+(2.52) \mathrm{x}+(-34.77) \text { eq }(5)
$$

where, $\mathrm{x}=$ calorific value $[\mathrm{MJ} / \mathrm{kg}] \mathrm{y}=\mathrm{NOx}[\mathrm{g} / \mathrm{kWh}]$

For pure fuel, the patterns of emissions of calorific value are illustrated and explained. The NOx emissions with a fixed load of $2000 \mathrm{rpm}$ are illustrated in Figure 5.

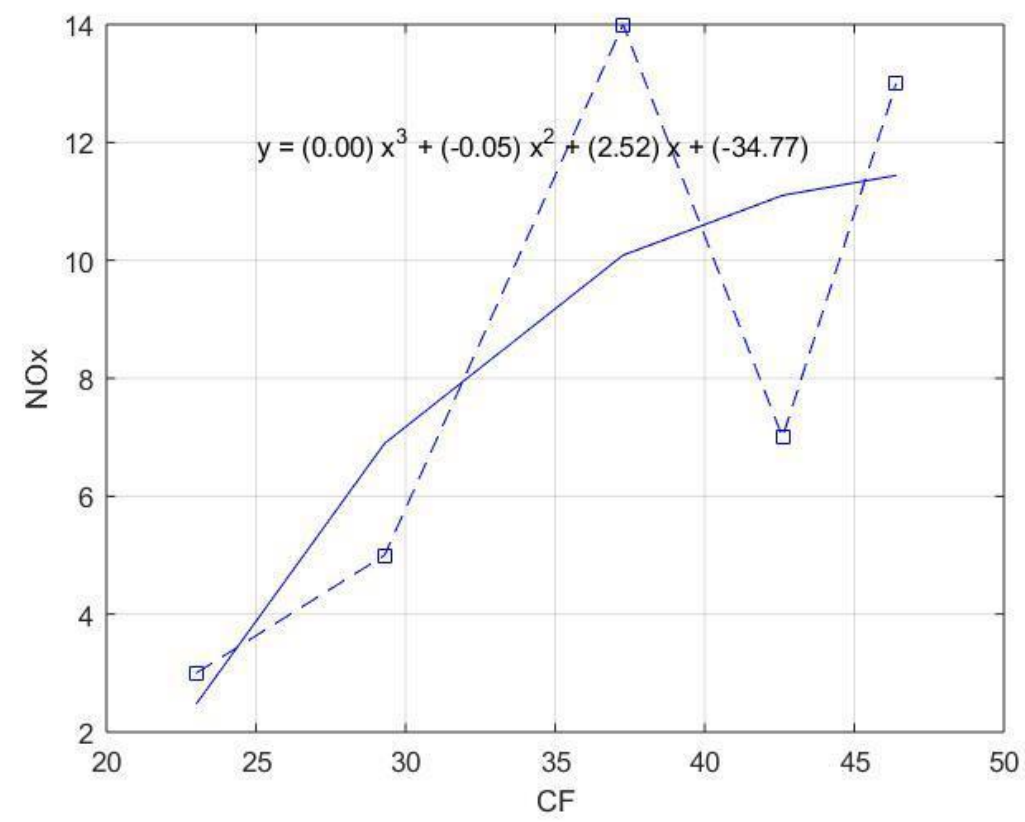

Figure.5. NOx and calorific value

The equation have derived from the MATLAB software is given in equation. 6 for piston bowl diameter

$\mathrm{y}=(0.01) \mathrm{x}^{3}+(-0.97) \mathrm{x}^{2}+(19.99) \mathrm{x}+(148.97)$ eq $(6)$

Where, $\mathrm{x}=$ diameter[mm]

$\mathrm{y}=\mathrm{NOx}[\mathrm{g} / \mathrm{kg}-$ fuel $]$

For pure gasoline, the trends of emissions for various bowl auxiliary diameters are illustrated and analysed. The NOx emissions for various bowl auxiliary diameters are 
presented in Figure 6.

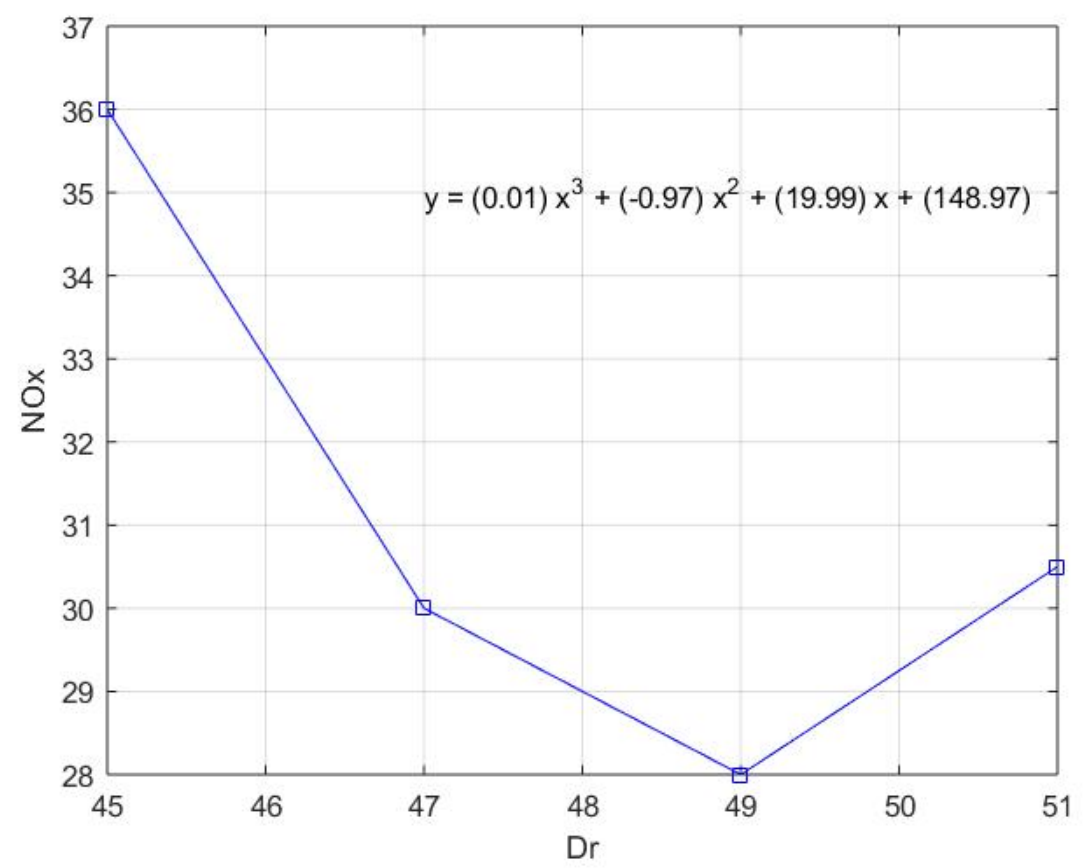

Figure.6. NOx and Piston bowl diameter (Dr)

\section{Conclusion}

NOx emission gradually increases first with increase in calorific value, complete combustion takes place which will rise the temperature of products above a certain adiabatic flame temperature level.

Higher temperature of combustion which in presence of high quantity of air, favours the production of Nox.

As bowl diameter increases, the NOX emission decreases gradually, bigger bowl diameter leads to low emission of exhaust toxic compounds, mainly reduces NOx emission.

\section{References}

[1] Hagen, D. and Holiday, G., "The Effects of Engine Operating and Design Variables on Exhaust Emissions," SAE Technical Paper 620404, 1962, https://doi.org/10.4271/620404.

[2] John B. Heywood, Internal Combustion Engine Fundamentals, Second Edition, McGraw-Hill Education, 2018

[3] B.M. Masum , H.H. Masjuki, M.A. Kalam, I.M. Rizwanul Fattah, S. M Palash, M.J. Abedin "Effect of ethanol-gasoline blend on NOx emission in SI engine", Renewable and Sustainable Energy Reviews 24 (2013) 209-222 
[4] Tan Tien Huynh · Minh Duc Le - DinhNghia Duong "Effects of butanol-gasoline blends on SI engine performance, fuel consumption, and emission characteristics at partial engine speeds", International Josurnal of Energy and Environmental Engineering

[5] D. S. Vijayan and J. J. Daniel, "An investigation on the torsional effect of symmetric moment resisting frame system subjected to eccentric reinforced concrete lift wall - A finite element approach," Int. J. Eng. Trends Technol., vol. 69, no. 8, pp. 179-184, 2021, doi: 10.14445/22315381/IJETT-V69I8P222

[6] Prof. DSc. DEng. Krzysztof Wisłocki, Poznan University of Technology, Faculty of Machines and Transport, Poznan ," Optical analysis of combustion chamber and fuel spray interaction in terms of chamber geometry modification and injection parameters change" , 2nd Conference on Engine Processes Proceedings , 2015 ,Berlin

[7] Jackson, M., Wiese, W., and Wentworth, J., "The Influence of Air-Fuel Ratio, Spark Timing and Combustion Chamber Deposits on Exhaust Hydrocarbon Emissions," SAE Technical Paper 620153, 1962, https://doi.org/10.4271/620153.

[8] Truedsson, I., Tuner, M., Johansson, B., and Cannella, W., "Emission Formation Study of HCCI Combustion with Gasoline Surrogate Fuels," SAE Technical Paper 2013-01-2626, 2013, https://doi.org/10.4271/2013-01-2626. 